\title{
Factors that Influence the Adoption of Postgraduate Online Courses
}

\author{
https://doi.org/10.3991/ijet.v13i12.8864 \\ Domingos Martinho( $\left.{ }^{\bowtie}\right)$, Eulália Santos, Ma Isabel Miguel, Dina Cordeiro \\ Higher Institute of Management and Administration, Santarém, Portugal \\ domingos.martinhodislasantarem.pt
}

\begin{abstract}
A research about factors that lead students to choose online courses, as well as the acceptance of these courses, can provide very relevant information for higher education institutions' decision makers to amend these offers to students' interests and needs. An investigation through questionnaire was developed involving students who attended online post-graduate courses. It was intended to know which factors affect students' decision to opt for postgraduate online courses. A model, based on the TAM (Technology Acceptance Model), was tested to find out what factors determine the intention to use online learning. The results shows that most respondents favour online courses and that their decision, when choosing this type of course, is mainly influenced by time management flexibility, avoiding going to school and the course curriculum interest. The test of the model, with structural equations, shows that attitude regarding online courses and perceived usefulness are factors that predict the intention to use. It was also concluded that the perceived ease of use induces a direct and indirect effect on the intention to use. The most significant results are consistent with published studies and can help the higher education institutions to define offer and communication strategies to reach a greater number of candidates for online learning.
\end{abstract}

Keywords—acceptance model; higher education; intention-to-use; online learning.

\section{$1 \quad$ Introduction}

Family and professional responsibilities condition the availability of adult students to attend school and become involved in academic activities, so the possibility of having proposals that are more flexible is a highly valued factor by these students [1] [2] [3].

The Allen and Seaman study [4], shows that institutions agreed that online education is critical to their long-term strategy. The importance of this subject, mainly for those responsible in organizing and promote these offers, it important aimed the needs and expectations of potential participants and it is important to know how they view online courses as an alternative to continue their studies. 
However, in spite of the importance of this subject, the study of the factors regarding acceptance of online learning, as well as the way they affect the students' decision, they are a little explored topics.

It is important adds information that can help institutional decision-makers and other stakeholders to position themselves more effectively in relation to the public they are looking for or may come to seek this type of distribution.

In general, the published studies investigate the attractiveness of the online courses, being this related to the costs, the ease of access and the inexistence of constraints related to time and place [1] [2] [5] [6] [7].

Regarding the analysis of other specific aspects an online course offers, published research points out the interest in course contents, institution reputation, the course and the teachers (institutional infrastructure, staff attitudes and skills) and perceived student expectations [7] [8] [9].

Not all individuals show the same inclination and interest to be involved in online courses. Factors such as discipline [4], motivation, technical competency, attitudes toward technology [10], perceiving ease of use, perceived usefulness, self-efficacy in the use of available technologies can condition the intention to use [11].

From the literature review emerge several theories and models that have in common the objective of explaining the intention to use through the relation between the behaviour and the attitudes, from which have come to appear proposals of adaptation and extension applied to different contexts the use of technologies. Among these theories and models, the technology acceptance model (TAM), proposed by Davis [12], stands out as the objective of providing an explanation of the general determinants of computer acceptance, capable of explaining the behaviour of the user in relation to the technologies of computation placed within reach of different types of population being, at the same time, parsimonious and theoretically justified.

TAM is based on the postulate that factors of primary importance in the accepting behaviours are perceived usefulness (PU) and perceived ease of use (PEU) (figure 1). According to Davis [12], a relation between perceived ease of use (PEU) and perceived usefulness (PU) that influences attitude (ATT) and this plays a mediating role in the intention to use (IU) the system.

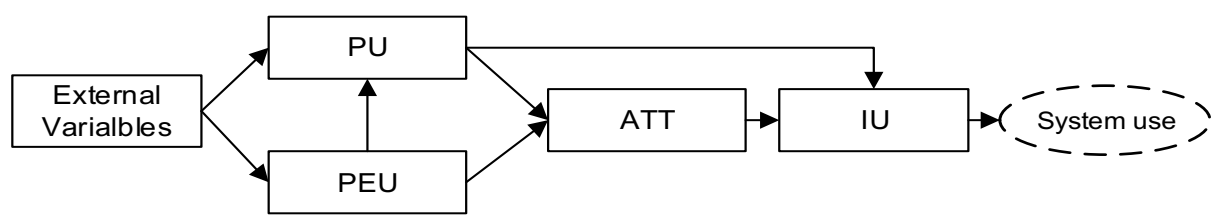

Fig. 1. TAM model (adapted from Davis (1989))

According to Davis [12], perceived usefulness (PU) refers to the degree to which the user considers that the use of technology will improve his/her performance. The perceived ease of use (PEU) is usually defined as the greater or lesser degree that an individual believes that using a technology does not require effort [11]. There are also a set of external variables, exogenous to the model, influencing perceived usefulness (PU) 
and/or perceived ease of use (PEU) that differ significantly according to published studies. In turn, the attitude (ATT) refers to the degree of interest that a user reveals in using a particular system [11] [13].

Although the TAM of Davis [12] was developed to explain and predict the acceptance of computer technologies in general, it has been applied in more specific contexts such as online teaching and learning [1] [11] [14] [15].

The consensus that has been generated over the last quarter century about TAM is evidenced by the several studies that make its application, as proposed by Davis [12], or presenting extensions and/or changes to the initial model [11] [14] [16] [17] [18].

The most recent works that adapting the TAM model to the specificities of the studied context, resulting in several proposals for extensions and/or changes. Park [19] identified several external variables in addition to perceived usefulness and perceived ease of use to explicate the determinants of users' acceptance decisions on e-learning systems. Liu et al. [20] take TAM as a foundation and extend the external variables as well as the perceived variables. Cheung and Vogel [11] used the TAM to highlight the factors that influence the acceptance of Google Applications for collaborative learning. According to the research results, the subjective norm represented by peers significantly moderates the relationship between attitude and intention toward the technology. Ibrahim et al. [17] conclude that computer self-efficacy has significantly effects on perceived ease of use, while perceived ease of use significantly affects intention to use e learning. Some studies [3] [21] used the TAM including external variables (self-efficacy, quality of work, system accessibility and subjective norm) confirmed the acceptability of the model to explain students' acceptance.

Although there is no agreement in the identified external variables, there is some consensus about factors related to environment features (course design, interface design, interaction, synchronous and asynchronous communication) and learners' features (self-efficacy, user technology experience) [16] [10] [11] [14] [19] [22] .

Despite the numerous proposals for combining, extending and/or changing multiple theories into a single model, the simplicity of the original TAM model [12] became a dominant model in investigating factors affecting users' acceptance of the technology [23] [24] [25]. A respectable amount of work dealing with the TAM, from its first appearance, more than a quarter century ago, clearly indicates that this model TAM is still quite appealing, leading to its use in various contexts and specifically in the one of online learning [26].

\section{$2 \quad$ Material and methods}

\subsection{Research questions}

This study aimed to answer the following research questions:

a) What factors affect students' decision to opt for postgraduate online courses?

b) What are the acceptance factors of postgraduate online courses? 
In order to answer these research questions, the following hypotheses have been formulated:

H1. Perceived usefulness is a predictor of the intention to use.

H2. Attitude is a predictor of the intention to use.

H3. Perceived usefulness has an effect on attitude.

H4. Perceived ease of use has an effect on perceived usefulness, attitude and intention to use.

H5. Technological experience has an effect on perceived usefulness and on attitude.

\subsection{Participants}

In this research, students who attended postgraduate training at three Portuguese higher education institutions participated voluntarily. There are collected 312 valid responses, corresponding to a response rate of $62.2 \%$, of which 502 were the total number of potential respondents.

The graph of Figure 2 shows the demographic characteristics of the study participants. Regarding gender, $87.2 \%$ of the respondents are women and $12.8 \%$ are men. The majority of the students are between the ages of 40 and 49 years old (53.2\%), followed by those who are 50 or older $(35.2 \%)$ and the remaining $11.5 \%$ are between the ages of 30 and 39 years old. As for the family situation, the majority of respondents are married (65.4\%), followed by single (15.4\%) and divorced (13.5\%) groups.

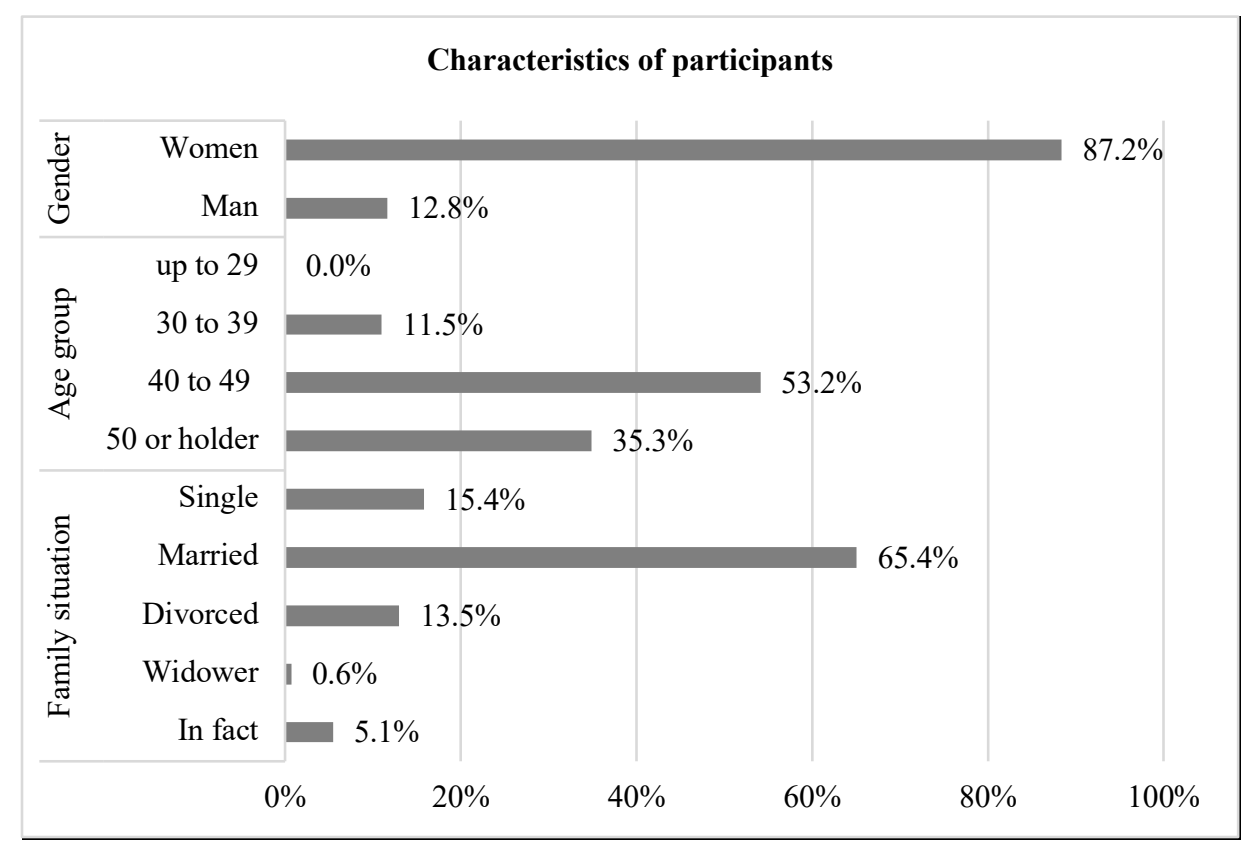

Fig. 2. Demographic characteristics of participants 


\subsection{Measure instrument}

The present research was done through a questionnaire developed and tested by Martinho [27]. It consists of four parts: the first is intended to obtain the general characteristics of the respondents (gender, age group and family situation); the second to have opinions about e-learning; the third part is about factors that affect the decision when choosing an online course (e-learning) and the fourth and last part, is to identify the experience in the use of information and communication technologies.

Regarding respondents' opinions about online courses, a 4-point Likert-type agreement scale was used (1-Strongly disagree; 2-Disagree in part; 3-Agree in part; 4Strongly agree), where it is intended to analyse attitude towards online education, online courses usefulness, intention to attend online courses, perceived ease of use and the favoured form of distribution. About preferred form of distribution, three types of distribution were considered: face-to-face, hybrid (30 to $79 \%$ online) and fully online [4].

In relation to the factors affecting the decision of the respondents when choosing an online course, a 4-point Likert scale was used (1-Nothing important, 2-Not important, 3-Considerably important, 4-Very important).

Were considered aspects related to: curiosity in knowing how online teaching works; distance between residence/place of work and school; avoiding trips to school (presence in the classroom); perceived ease of use of online learning systems; flexibility in time management; interest in the course curriculum; possibility to learn at my pace; possibility of working with students from other schools; cost reduction; reputation of the school; reputation of the faculty and reputation of the course.

Finally, in order to analyze the experience of respondents in the use of information and communication technologies, a 4-point Likert scale was used (1- None; 2 - Up to 3 years of experience; 3- 3 to 6 years of experience; 4- More than 6 years of experience). In this way, the experience of using word processor, e-mail, PowerPoint (slide show) software, search engines (Google, Yahoo), online meeting systems (Skype, Cisco WebEx, etc.), MP3 and MP4 players (iPods), discussion groups, electronic communication tools (chat, messenger), collaborative work tools (Google Drive, YouTube, etc.) and learning environments online (Moodle).

In the study by Martinho [27], all constructs and their dimensions presented Cronbach's alpha values above 0.8 , which shows a good internal consistency [28], which justifies its use in this study.

\subsection{Procedures}

The 502 potential respondents were previously informed about the study's objectives and the confidentiality and anonymity of the information provided, through an email, which included the online link to the questionnaire. Fieldwork was developed during the third quarter of 2017.

The statistical treatment of the data was performed using SPSS and AMOS software from IBM. To achieve the characterization of the respondents and the general analysis to some items of the questionnaire, we used the descriptive statistics. Since the 
assumptions for the application of the parametric tests were not verified, the nonparametric statistical inference techniques were used, namely: Mann-Whitney test for comparison of two independent samples and Kruskal-Wallis test for comparison of three or more independent samples [29]. We also applied the technique of confirmatory factorial analysis and the calculation of Cronbach's Alpha values to confirm the factorial structure and to study the internal consistency of the factors that constitute the measurement instruments [30]. In order to test the formulated research hypotheses, we used the structural equations model [31].

\section{$3 \quad$ Results}

\subsection{Preferred form of distribution}

As can be seen in Figure 3, most participants (60.9\%) prefer fully online courses, while $34.0 \%$ would choose hybrid courses (face-to-face and online), and only $5.1 \%$ face-to-face courses.

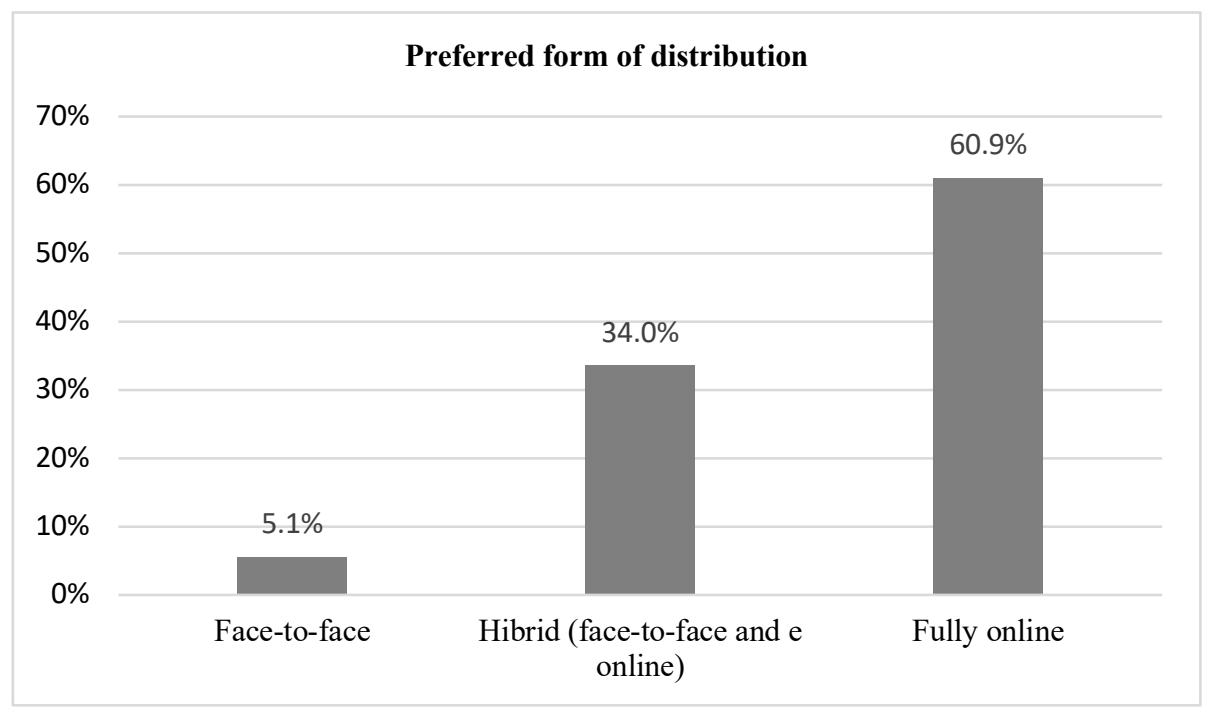

Fig. 3. Preferred form of distribution by participants

\subsection{Factors affecting decision when choosing online courses}

Table 1 summarizes the importance recognized by respondents when faced with factors that affect the decision in choosing an online course, ranked from the most important to the least important. The flexibility in the management of time presents the highest average $(\mathrm{M}=3.90 ; \mathrm{SD}=0.31)$, followed by avoiding trips to school $(\mathrm{M}=3.79$; $\mathrm{SD}=0.42)(\mathrm{M}=3.76 ; \mathrm{SD}=0.46)$ and interest in the course curriculum $(\mathrm{M}=3.73 ; \mathrm{SD}$ $=0.48$ ). Among the less valued items are curiosity about how online education works 
$(\mathrm{M}=2.88 ; \mathrm{SD}=0.93)$ and possibility of working with students from other schools $(\mathrm{M}$ $=3.14 ; \mathrm{SD}=0.85$ ).

Table 1. Factors affecting decision when choosing an online course.

\begin{tabular}{|c|l|c|c|}
\hline N. $^{\circ}$ & \multicolumn{1}{|c|}{ Item } & M & SD \\
\hline S3.2 & Flexibility in time management & 3.90 & 0.31 \\
\hline S3.10 & Avoid trips to school & 3.79 & 0.42 \\
\hline S3.5 & Possibility to learn at my own pace & 3.76 & 0.46 \\
\hline S3.1 & Interest in the course curriculum & 3.73 & 0.48 \\
\hline S3.12 & Distance between residence / place of work and school & 3.66 & 0.65 \\
\hline S3.7 & Reduction of costs & 3.60 & 0.63 \\
\hline S3.4 & Course reputation & 3.51 & 0.55 \\
\hline S3.9 & Ease of use of course support technology & 3.42 & 0.60 \\
\hline S3.6 & School Reputation & 3.40 & 0.62 \\
\hline S3.3 & Possibility of working with teachers from other schools & 3.36 & 0.58 \\
\hline S3.8 & Possibility of working with students from other schools & 3.14 & 0.85 \\
\hline S3.11 & Curiosity about how online education works & 2.88 & 0.93 \\
\hline
\end{tabular}

\subsection{Relationship between demographic variables and factors most valued by} students

The relationship between demographic variables and the six factors most valued by students to choose online courses was as follows: flexibility in time management (S3.2); avoid trips to school (S3.10); possibility to learn at my own pace (S3.5); interest in the course curriculum (S3.1); distance between residence / place of work and school (S3.12) and cost reduction (S3.7).

As can be seen in Table 2, Mann-Whitney and Kruskal-Wallis tests showed significant differences in the factor cost reduction (S3.7) relative to the family situation variable $(\mathrm{p}<0.05)$, with the in fact $(M=3.00, S D=0.93)$ and divorced $(M=3.37, S D=$ $0.76)$ groups to value less cost reduction and single $(M=3.67, S D=0.58)$ and married $(M=3.67, S D=0.55)$ to value more

Table 2. Relationship between demographic variables and factors most valued by students.

\begin{tabular}{|c|c|c|c|c|c|c|c|}
\hline $\begin{array}{c}\text { Demographic varia- } \\
\text { bles }\end{array}$ & Test & S3.2 & S3.10 & S3.5 & S3.1 & S3.12 & S3.7 \\
\hline \multirow{3}{*}{ Gender } & U Mann-Whitney & 1005.00 & 1053.00 & 888.00 & 1080.50 & 1018.00 & 1027.50 \\
& $\mathrm{Z}$ & -1.06 & -0.38 & -1.75 & -0.13 & -0.63 & -0.51 \\
& $\mathrm{p}$ & 0.288 & 0.701 & 0.080 & 0.898 & 0.532 & 0.610 \\
\hline \multirow{3}{*}{ Age group } & Qui-quadrate & 0.40 & 2.09 & 3.55 & 1.47 & 1.10 & 1.54 \\
& $\mathrm{Df}$ & 2 & 2 & 2 & 2 & 2 & 2 \\
\hline \multirow{3}{*}{ Family situation } & $\mathrm{p}$ & 0.820 & 0.352 & 0.170 & 0.480 & 0.577 & 0.463 \\
\hline & Qui-quadrate & 4.62 & 3.71 & 2.96 & 3.05 & 4.38 & 11.92 \\
& $\mathrm{Df}$ & 5 & 5 & 5 & 5 & 5 & 5 \\
& $\mathrm{p}$ & 0.465 & 0.592 & 0.707 & 0.693 & 0.496 & $0.036^{*}$ \\
\hline
\end{tabular}




\subsection{Relationship between the preferred form of distribution and the factors most valued by students}

Kruskal-Wallis test was applied to determine if there is a relationship between the preferred distribution form and the factors most valued by the students. In Table 3 , it is possible to observe that there are statistically significant differences $(p<0.05)$ in the factors: avoid trips to school (S3.10), interest in the course curriculum (S3.1) and distance between residence / work and school (S3.12) among the three preferred forms of distribution: face-to-face, hybrid (face-to-face an online) and fully online.

Table 3. The relationship between the preferred form of distribution and the factors most valued by students.

\begin{tabular}{|c|c|c|c|c|c|c|}
\hline & S3.2 & S3.10 & S3.5 & S3.1 & S3.12 & S3.7 \\
\hline Qui-quadrado & 3.17 & 21.68 & 1.42 & 7.87 & 6.21 & 2.20 \\
\hline Df & 2 & 2 & 2 & 2 & 2 & 2 \\
\hline $\boldsymbol{p}$ & 0.205 & $0.000^{* *}$ & 0.493 & $0.020^{*}$ & $0.045^{*}$ & 0.332 \\
\hline
\end{tabular}

${ }^{*} p<0.05 ; * * p<0.01$

Table 4 shows the obtained means for each factors in which there was statistical significance between the elements most valued by the students and the preferred form of distribution. Thus, it is concluded that students who prefer fully online courses and those who prefer hybrid courses (face-to-face and online) confer greater importance to the factor avoid trips to school (S3.10), while those who prefer face-to-face courses value the factor interest by the curriculum (S3.1).

Table 4. Averages of factors where the relationship with statistical significance is grouped according to the preferred distribution form.

\begin{tabular}{|c|c|c|c|c|}
\hline Preferred distribution form & & S3.10 & S3.1 & S3.12 \\
\hline \multirow{2}{*}{ Face-to-face } & $\mathrm{M}$ & 3.38 & 4.00 & 3.63 \\
\cline { 2 - 5 } & $\mathrm{SD}$ & 0.74 & 0.00 & 0.52 \\
\hline \multirow{2}{*}{ Hibrid (face-to-face and online) } & $\mathrm{M}$ & 3.63 & 3.59 & 3.49 \\
\cline { 2 - 5 } & $\mathrm{SD}$ & 0.49 & 0.54 & 0.77 \\
\hline \multirow{2}{*}{ Fully online } & $\mathrm{M}$ & 3.92 & 3.78 & 3.76 \\
\cline { 2 - 5 } & $\mathrm{SD}$ & 0.27 & 0.45 & 0.57 \\
\hline
\end{tabular}

\subsection{Online Courses Acceptance Model (OCAM)}

The online courses acceptance model (OCAM) that is intended to test is based on the TAM model [12], which, like the suggestions presented in other studies [11] [14] [32], presented in figure 4, which includes the following dimensions (factors):

- Perceived usefulness (PU). It is understood in the same sense as Davis [12] and other authors who have been applying the concept, that is, the degree to which students consider that online teaching can improve their performance;

- Attitude (ATT). Demonstrated by students in relation to online teaching; 
- The technological Experience. Obtained from the students' responses in which they quantify their experience, relating it to the use of various technologies. Two external variables were introduced: Base technological experience (BTE) and advanced technological experience (ATE), arriving at the model.

- Perceived ease of use (PEU). Perceived by students who participated in the study;

- Intention to use (IU). Measuring the degree to which students are interested in using online courses.

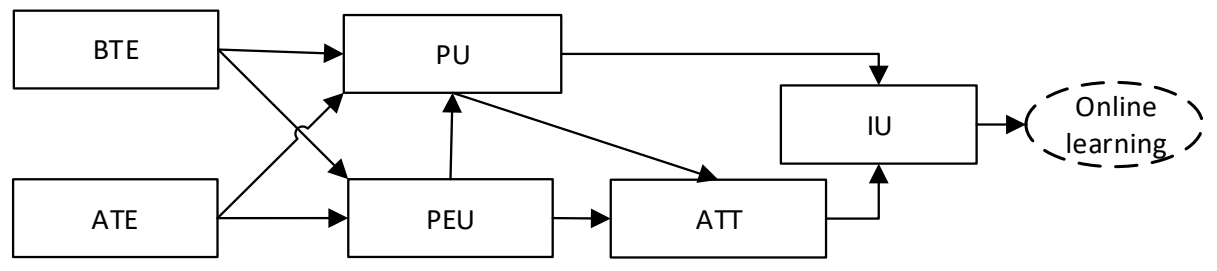

Fig. 4. Acceptance online courses model (AOCM)

Online Courses Acceptance Model (OCAM) test. In order to test the Online Courses Acceptance Model (OCAM), modelling was done using structural equations. The study was carried out in two phases: confirmatory factor analysis and path analysis.

Confirmatory Factor Analysis. The first phase consisted of the application of the confirmatory factorial analysis (through the measurement model) in order to confirm the factorial structure of the constructs under study and through the calculation of Cronbach's Alpha to evaluate the quality of the latent variables and their respective constructs [31].

The result obtained in the analysis of the second section of the questionnaire with eigenvalues $\geq 1$ [28], presented in Table 5, explains $79.0 \%$ of the total variance, distributed as follows: factor 1 - Attitude: $39.4 \%$; factor 2 - Intention to use: $16.6 \%$; factor 3 - Perceived usefulness: $12.8 \%$ and factor 4 - Ease of use: $10.3 \%$, with the relation between the variance extracted by each factor and the total variance $>5 \%$ [33].

This result is acceptable from the point of view regarding statistical method. The values of Cronbach's Alpha, presented in Table 5, show that the instrument reveals adequate internal consistency [30].

The obtained result in the analysis of the third section (Table 6), using the same conditions as in the previous one, explains $64.9 \%$ of the total variance, distributed by two factors: factor 1 - Base Technological Experience (BTE): $36.8 \%$ and factor 2 Advanced Technological Experience (ATE): 28.1\%. The items related to Base Technological Experience (BTE) have higher values than items related to Advanced Technological Experience (ATE).

The values obtained in Cronbach's Alpha (Table 6), show that the instrument reveals good internal consistency [30]. 
Table 5. Organization of latent variables (factors).

\begin{tabular}{|c|c|c|c|c|}
\hline \multirow{2}{*}{ Items } & \multicolumn{4}{|c|}{ Factors } \\
\hline & 1 & 2 & 3 & 4 \\
\hline S2.1 - For me there are no differences in learning in face-to-face or online. & 0.95 & & & \\
\hline S2.2 - The frequency of online courses can help me to progress in my career. & & & 0.92 & \\
\hline $\begin{array}{l}\text { S2.3 - The frequency of online courses can help me to improve my eco- } \\
\text { nomic conditions. }\end{array}$ & & & 0.81 & \\
\hline $\begin{array}{l}\text { S2.4 Learning to operate applications to support online courses is easy for } \\
\text { me. }\end{array}$ & & & & 0.89 \\
\hline S2.5 - Online courses has the same academic rigor as face-to-face courses. & 0.95 & & & \\
\hline $\begin{array}{l}\text { S2.6 - The frequency of online courses is a good way to acquire new } \\
\text { knowledge. }\end{array}$ & & 0.73 & & \\
\hline S2.7 - I am interested in attending online courses in the future. & & 0.73 & & \\
\hline $\begin{array}{l}\text { S2.8 - It is easy to improve my skills in using online courses support appli- } \\
\text { cations. }\end{array}$ & & & & 0.80 \\
\hline S2.9 - Online courses are recognized in the job market. & 0.95 & & & \\
\hline $\begin{array}{l}\text { S2.10 - The frequency of online courses helps me to improve my profes- } \\
\text { sional skills. }\end{array}$ & & & 0.89 & \\
\hline S2.11 - I plan to advise my friends to enrol in online courses. & & 0.75 & & \\
\hline S2.12 - Overall, online courses support applications are easy to use. & & & & 0.74 \\
\hline S2.13 - Online courses have more advantages than disadvantages. & & 0.81 & & \\
\hline Cronbach's Alpha & 0.995 & 0.819 & 0.861 & 0.795 \\
\hline
\end{tabular}

Table 6. Organization of latent variables related to experience in the use of ICT.

\begin{tabular}{|l|c|c|}
\hline \multicolumn{1}{|c|}{ Experience in using: } & \multicolumn{2}{c|}{ Factors } \\
\cline { 2 - 3 } & \multicolumn{1}{c|}{$\mathbf{1}$} \\
\hline S4.1 - word processor (Word) & & 0.95 \\
\hline S4.2 - email & & 0.87 \\
\hline S4.3 - slide show software (PowerPoint) & & 0.87 \\
\hline S4.4 - search engines (Google, Yahoo) & & 0.80 \\
\hline S4.5 - online meeting systems (Skipe, Cisco WebEx, etc.) & 0.79 & \\
\hline S4.6 - MP3 and MP4 Player (iPod) & 0.77 & \\
\hline S4.7 - discussion groups & 0.83 & \\
\hline S4.8 - electronic communication tools (chat, messenger) & 0.74 & \\
\hline S4.9 - collaborative work tools (Google Drive, Youtube, etc.) & 0.66 & \\
\hline S4.10 - online learning environments (Moodle) & 0.71 & \\
\hline Cronbach's Alpha & 0.886 & 0.846 \\
\hline
\end{tabular}

\section{Structural equation analysis}

Preliminary confirmations. The verification of the multivariate outliers, through the Mahalanobis distance (DM2) [31], revealed three observations with very high values (with p1 and $\mathrm{p} 2<0.001$ ) that were removed, passing the sample to 309 valid results. In the verification of the multivariate normality of the data through asymmetry $(\mathrm{sk}<2)$ and kurtosis $(\mathrm{ku}<7)$, no severe deviations were detected that could jeopardize 
the application of the maximum likelihood estimation method [31]. Also in the preliminary evaluation of the model, a multicollinearity diagnosis was made. The result obtained did not reveal problems of excessive association between the variables (Tolerance $>0.1$ and $\mathrm{VIF}<5$ ) [31].

Confirmation of the measurement model. The estimation of the model of measurement verified that presents a good adjustment as can be seen by the analysis of the main indices $\left(\mathrm{X}^{2}(215)=260.927 ; \mathrm{p}=0.018 ; \mathrm{X}^{2} / \mathrm{df}=1.214\left(\mathrm{X}^{2} / \mathrm{df}<2\right) ; \mathrm{CFI}=0.983\right.$ $(\mathrm{CFI}>=0.95) ; \quad \mathrm{GFI}=0.883 \quad(\mathrm{GFI}>=0.85) ; \mathrm{NFI}=0.911 \quad(\mathrm{NFI}>0.90) ; \quad \mathrm{RMSEA}=0.037$ $(\mathrm{RMSEA}<0.05)$; MECVI=2.670). It is also verified that all items have high factorial weights $(>0.5)$ and, consequently, the factors present factorial validity [31] (Figure 5).

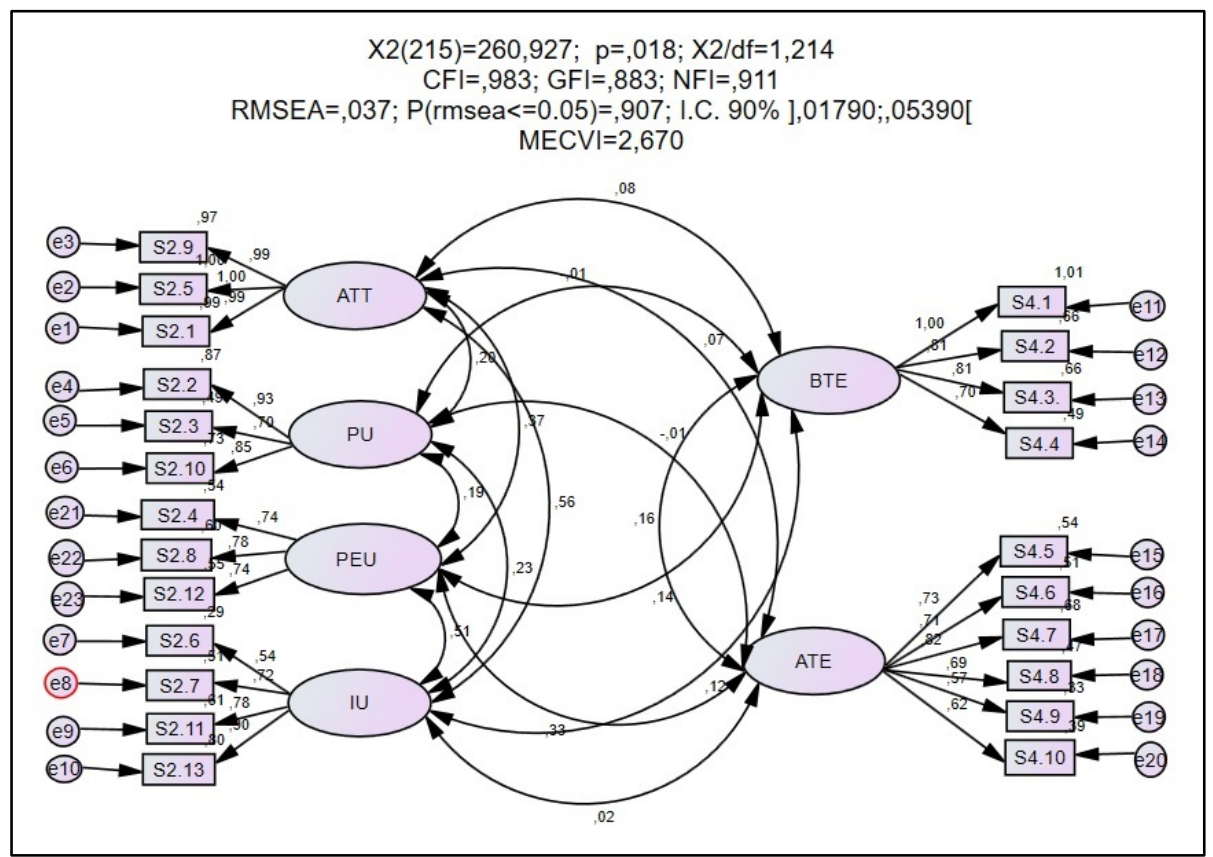

Fig. 5. Measurement Model

Analysis of the change indexes for covariance between variables revealed that the correlation between the $\mathrm{e} 3 \leftrightarrow \mathrm{e} 8$ error residues $(\mathrm{MI}=18.8)$ would improve the quality of the adjustment [31]. The analysis of the measurement model was performed, correlating the residuals of the errors $\mathrm{e} 3 \leftrightarrow \mathrm{e} 8$, obtaining the estimation model that reveals the improvement $\quad\left(\mathrm{X}^{2} \quad(214)=240.420 ; \quad \mathrm{p}=0.104 ; \quad \mathrm{X}^{2} / \mathrm{df}=1.123 \quad\left(\mathrm{X}^{2} / \mathrm{df}<2\right) ; \quad \mathrm{CFI}=0.990\right.$ $(\mathrm{CFI}>=0.95) ; \mathrm{GFI}=0.890 \quad(\mathrm{GFI}>=0.85) ; \quad \mathrm{NFI}=0.918 \quad(\mathrm{NFI}>0.90) ; \quad \mathrm{RMSEA}=0.028$ $(\mathrm{RMSEA}<0.05)$; MECVI=2.550).

Causal model Specification. The results of the model with standardized estimates, shown in Figure 6, show a good fit $\left(\mathrm{X}^{2}(220)=260.978 ; \mathrm{p}=0.030 ; \mathrm{X}^{2} / \mathrm{df}=1.186\right.$ $\left(\mathrm{X}^{2} / \mathrm{df} 2<2\right) ; \quad \mathrm{CFI}=0.985 \quad(\mathrm{CFI}>=0.95) ; \quad \mathrm{GFI}=0.880 \quad(\mathrm{GFI}>0.85) ; \quad \mathrm{NFI}=0.911$ $(\mathrm{NFI}>=0.90)$; RMSEA $=0.035(\mathrm{RMSEA}<0.05) ; \mathrm{MECVI}=2.592)$. 


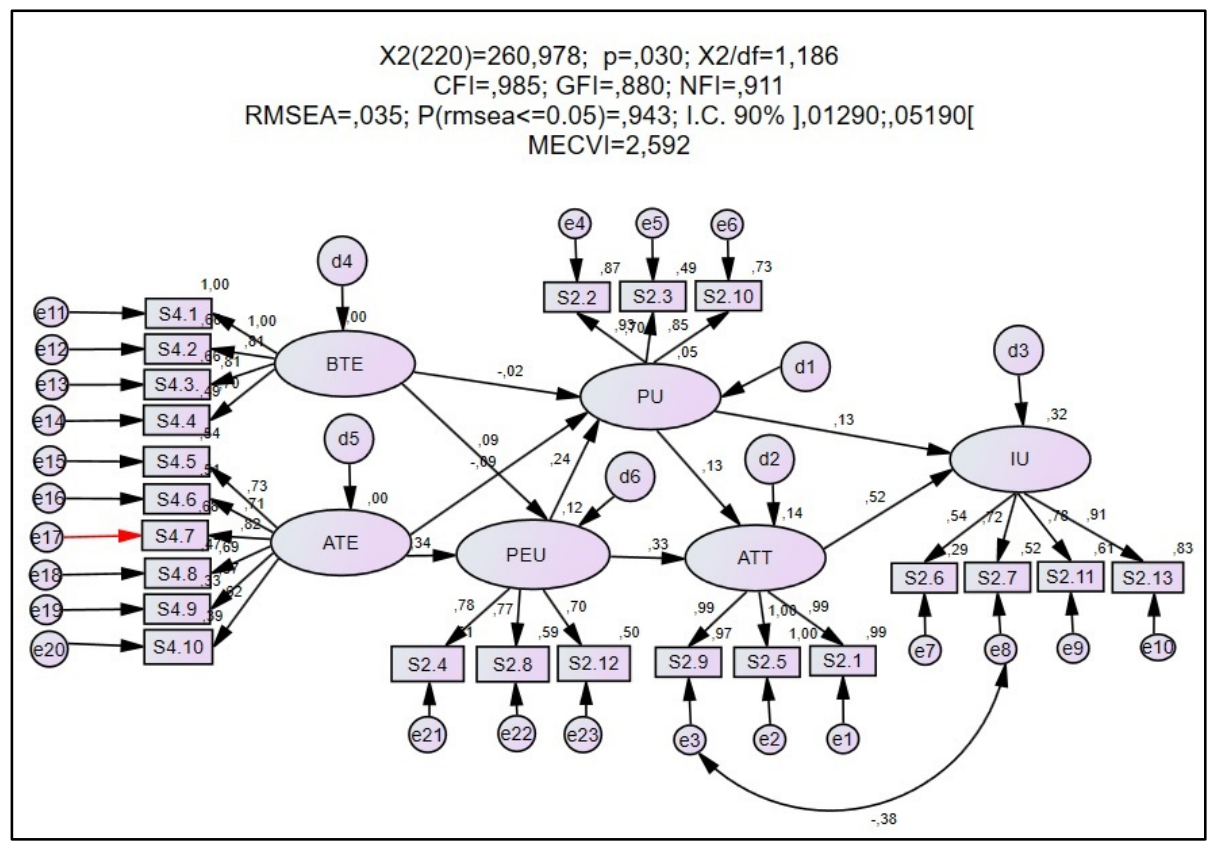

Fig. 6. Causal model

Standardized effects. The analysis of the total effects (Table 7) shows that the effect of the Attitude (ATT) factor on the Intention to use (IU) is 0.524 whose value corresponds in total to the direct effect (Table 8). Total effect of the Perceived Usefulness (PU) on the Attitude (ATT) is 0.130 and the effect of the Perceived Usefulness (PU) factor on the Intention to use (IU) is 0.195 . These values correspond almost entirely to the values of the direct effects as can be observed in Table 8 .

The effect of Perceived Ease of Use (PEU) on Perceived Usefulness (PU) (0.037) and Attitude (ATT) (0.357) factors is obtained almost entirely through their direct effects (Table 8), while the indirect effect of Perceive Ease of Use (PEU) on Intention to use (IU) is 0.217 (Table 9).

The effect of the Base Technological Experience (BTE) and Advanced Technological Experience (ATE) factors on Intention to use (IU) are very insignificant (0.055 and 0.015 respectively) (Table 7). However, there is a significant direct effect between Advanced Technological Experience (ATE) factor and Perceived Ease of Use (PEU) (0.335), as well as an indirect effect of Advanced Technological Experience (ATE) on Attitude (ATT) (0.108) and Perceived Utility (PU) (0.079) factors, although this is smaller than that. The Base Technological Experience (BTE) has a reduced direct effect on Intention to use (IU) (0.090). 
Table 7. Standardized total effects.

\begin{tabular}{|c|c|c|c|c|c|c|}
\hline & ATE & BTE & EU & PU & ATT & IU \\
\hline EU & 0.335 & 0.090 & 0.000 & 0.000 & 0.000 & 0.000 \\
\hline PU & -0.010 & -0.003 & 0.237 & 0.000 & 0.000 & 0.000 \\
\hline ATT & 0.108 & 0.029 & 0.357 & 0.130 & 0.000 & 0.000 \\
\hline IU & 0.055 & 0.015 & 0.217 & 0.195 & 0.524 & 0.000 \\
\hline
\end{tabular}

Table 8. Standardized direct effects.

\begin{tabular}{|c|c|c|c|c|c|c|}
\hline & ATE & BTE & EU & PU & ATT & IU \\
\hline EU & 0.335 & 0.090 & 0.000 & 0.000 & 0.000 & 0.000 \\
\hline PU & -0.089 & -0.024 & 0.237 & 0.000 & 0.000 & 0.000 \\
\hline ATT & 0.000 & 0.000 & 0.326 & 0.130 & 0.000 & 0.000 \\
\hline IU & 0.000 & 0.000 & 0.000 & 0.127 & 0.524 & 0.000 \\
\hline
\end{tabular}

Table 9. Standardized indirect effects.

\begin{tabular}{|c|c|c|c|c|c|c|}
\hline & ATE & BTE & EU & PU & ATT & IU \\
\hline EU & 0.000 & 0.000 & 0.000 & 0.000 & 0.000 & 0.000 \\
\hline PU & 0.079 & 0.021 & 0.000 & 0.000 & 0.000 & 0.000 \\
\hline ATT & 0.108 & 0.029 & 0.031 & $\underline{0.000}$ & 0.000 & 0.000 \\
\hline IU & 0.055 & 0.015 & 0.217 & 0.068 & 0.000 & 0.000 \\
\hline
\end{tabular}

The most important results obtained, summarized in Figure 7, were as follows:

- Intention to choose online learning is largely determined by the students' Attitude (ATT) towards online courses (0.524) in a more moderate way, by the Perceived Ease of Use (PEU) (0.217) and the Perceived Usefulness (PU) (0.195).

- Perceived ease of use (PEU) attained a positive direct influence on PU. Perceived ease of use (PEU) also attained a direct effect on attitude (ATT) and intention to use (IU).

- Technological experience is a predictor of the Intention to use (IU). There were effects, with statistical significance of the Advanced Technological Experience (ATE) in relation to Perceived Ease of Use (PEU) and, even more moderately, in relation to Perceived Usefulness (PU) and Attitude (ATT). The Base Technological Experience (BTE) also has a reduced direct effect on the Perceived Ease of Use (PEU).

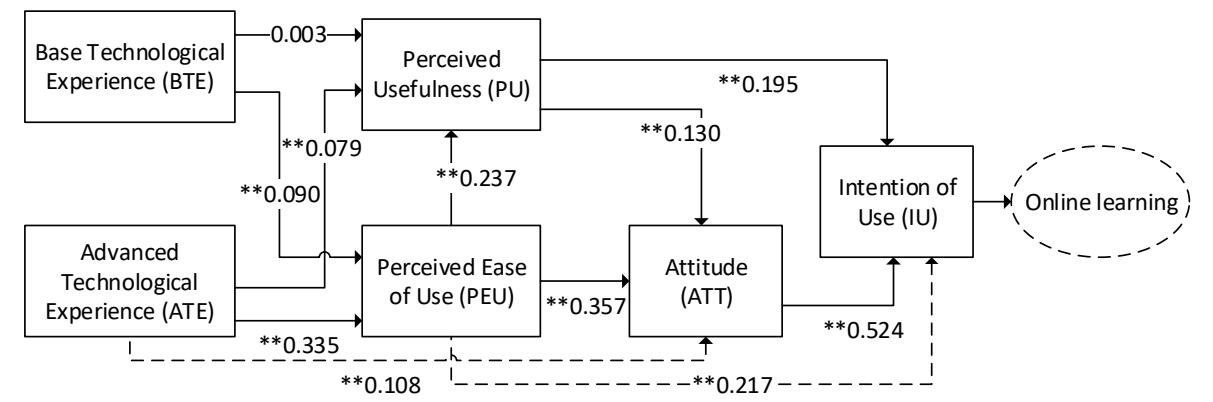

Fig. 7. Acceptance online courses model (AOCM) test results 


\section{Discussion}

\subsection{Factors that affect students' decision to opt posgraduate online courses}

The study participants classified, in descending order of importance when choosing online courses, the following factors:

- Flexibility in time management;

- Avoiding trips to school (presence in the classroom);

- Possibility to learn at my own pace;

- Interest in the course curriculum;

- Distance between the residence / work place and the school;

- Reduction of costs;

- Reputation of the course;

- Perceived ease of use of course support technology;

- Reputation of the school;

- Possibility of working with teachers from other schools;

- Possibility of working with students from other schools;

- Curiosity in knowing how online teaching works.

The flexibility in time management emerges as an important aspect for choosing online courses, confirming the conclusions of most of the studies on this subject [2] [5] [6].

While flexibility in time management is a cross-cutting and consensual factor for all students, it is concluded that students who prefer fully online courses value the aspects related to avoiding trips to school and distance between residence / workplace and school, while those who prefer face-to-face courses point to interest in the course curriculum as the main deciding factor for joining online courses. We may conclude that those who prefer totally online courses do so mainly for utilitarian reasons, while others, despite expressing a preference for face-to-face courses, do not fail to become involved in online courses by presenting interest in the course curriculum with an above average weight in that decision. It is also interesting to note that the interest in the curriculum of the course assumes the same importance as that attributed to it in other studies, namely [9].

The possibility to learn at my own pace emerges as a factor highly valued by students, which is a significant difference from previous studies [9].

The cost reduction (sixth position) seems to be in line with the conclusions of studies conducted with students enrolled in online courses [5] [9] and are inconsistent with the results of other researchers [7] who showed the importance of this item.

The perceived ease of use of the technology to support the course rises in the ranking of the most important factors while choosing online learning, in relation to the position that was attributed in others studies [5] [9]. This increase may be related to the technological evolution during the period between these studies, and it is natural that the current students, with more user-friendly technologies, recognize the importance of this factor. 
The reputation of the course appears in seventh place assuming less importance in relation to the conclusions of other studies [7] where this factor occupies a more important place. The low importance given by students to the factors related to institutional infrastructure and staff are different from those obtained by King and Boyatt [8] where these aspects are highly valued.

As regards factors that are less valued by students, there is agreement with other studies [5] [7], where curiosity about working with teachers and students of the other schools, opportunity to know e-learning and its benefits are among the factors less valued.

\subsection{Acceptance factors of postgraduate online courses}

Confirmatory factor analysis about technological experience factors determined the existence of two external variables: Base Technological Experience (BTE) and Advanced Technological Experience (ATE) that were introduce in the OCAM (Online Courses Acceptance Model) tested. This shows differences in relation to other studies [11] [15] that not detect differences about technological experience.

The results of this study provide support for the research model and for the hypotheses regarding the directional linkage among the model's variables. The tested hypotheses were confirmed, namely:

H1. Perceived usefulness (PU) is a predictor of the Intention to use (IU).

H2. Attitude (ATT) is a more significant predictor of the Intention to use (IU).

H3. Perceived Usefulness (PU) has an effect on Attitude (ATT).

H4. Perceived Ease of Use (PEU) has direct effect of predicting the Intention to use (IU) and indirect on Perceived Usefulness (PU) and Attitude (ATT).

H5. Advanced Technological Experience (ATE) has an effect mainly on Perceived Ease of Use (PEU) but also on Perceived Usefulness (PU) and on Attitude (ATT).

The Base Technological Experience (BTE) has a reduced effect on the Perceived Ease of Use (PEU).

Results showed that Attitude (ATT) is the most important in determining Intention to use (IU) online learning. These results confirm the conclusions of Lai et al. [10] and are significantly different from those obtained by Cheung and Vogel [11], in which it was concluded that Perceived Usefulness (PU) is the factor that most determines the Intention to use (IU) online learning.

Although with less importance with what TAM postulates [12], and confirmed by other studies [3] [21], Perceived Usefulness (PU) have a significant influence on the Perceived Intention to use (PEU).

Perceived Ease of Use (PEU) attained a positive direct influence on Perceived Usefulness (PU) similar finding in other studies [1] [17] [22]. Perceived Ease of Use (PEU) also attained a direct effect on Attitude (ATT) and Intention to use (IU), which is in agreement with some published studies [11] [20], which concludes that, although it is not so intense, there is a prediction relation between these variables.

As concluded by other studies [15] the Technological Experience is a predictor of the Intention to use (IU). 


\section{Conclusions}

Higher Education Institutions (HEIs) that decide to have online education offers, must work hard when designing and implementing this kind of education allowing attracting students to these new form of learning. There are a large number of potential candidates in the future to attend online courses, and it is up to HEIs to develop the frequency conditions and communication strategies that will lead these candidates to opt for these forms of distribution.

The findings of this study suggest that factors like flexibility in time management and the advantage related to the elimination of trips to school should be considered as important arguments in the communication strategies about online courses. These strategies are even more important because the target audience of postgraduate online courses are adults with family and professional responsibilities for whom these factors have greater importance.

The school reputation and course reputation variables are the result of an aggregate set of many factors that are not unique to online courses, which, as in face-to-face teaching, constitute variables to be consolidated and developed in the context of practice of HEIs. With regard to the improvement in the reputation of the school offered by the online courses, it is expected that the HEIs in relation to online education, the same type of rigor that they put in face-to-face teaching.

The investment in communication strategies that emphasize the usefulness of online courses and the perceived ease of use of this form of distribution, usually associated with the technologies used, may be factors that lead some of those interested in attending postgraduate training to opt for online courses.

The results obtained need to carry out additional empirical work that can contribute to amplify or alter the conclusions obtained, so that the conclusions can be generalized to the universe of all public and private HEIs. The limitations of this study consist of three main issues. First, the findings and their implications presented here were obtained from a single HEI. Thus, caution is necessary when generalizing the findings to other user groups or different contexts. Second, responses to the study were voluntary and thus inevitably subject to self-selection biases. Consequently, users who were interested in, had used, or were currently involved in online courses may have been more likely to respond to the survey. To resolve this issue, future research efforts should be conducted to test the proposed model using a large number of students involved in several online courses. Third, there may be a need to search for additional variables that will improve the Online Courses Acceptance Model. Future researchers can investigate other variables, such as discipline of learners and self-efficacy.

The future work also goes through the deepening of the study on the acceptance models, orienting it to the following aspects: Investigate the effect of previous experience of attending online courses; to deepen the comparison between the results obtained with students who attend online courses and those who attend face-to-face courses. 


\section{$6 \quad$ References}

[1] Al-Gahtani S. S. (2016. Empirical investigation of e-learning acceptance and assimilation: A structural equation model. Applied Computing and Informatics Vol. 12, Issue 1, 27-50. https://doi.org/10.1016/j.aci.2014.09.001

[2] Garrison, D.R, Anderson T., \& Archer, W. (2013). A Theory of Critical Inquiry in Online Distance Education in Handbook of Distance Education, New York, Routledge, 113-128.

[3] A. Tarhini, K. Hone and X. Liu (2015). A cross-cultural examination of the impact of social, organisational and individual factors on educational technology acceptance between British and Lebanese university students. BJET - British Journal of Educational Tehenology, Vol. 46, Issue 4, 739-755. https://doi.org/10.1111/bjet.12169

[4] Allen, I. E. \& Seaman, J. (2015). Tracking Online Education in the United States. Babson Survey Research Group and Quahog Research Group, LLC.

[5] Lemos, S. \& Pedro, N (2013). Expetativas e Satisfação dos Estudantes em Cursos em Elearning no Ensino Pós-Graduado. ETD-Educação Temática Digital, Vol. 15, No 1, $107-$ 126. https://doi.org/10.20396/etd.v15i1.1297

[6] Henderson, M., Selwyn, N. \& Aston, R. (2017). What works and why? Student perceptions of 'useful digital technology in university teaching and learning. Journal Studies in Higher Education, Vol. 42, Issue 8, 1567-1579. https://doi.org/10.1080/03075079.2015.1007946

[7] Zhang, L., Wen, H., Li, D., Fu, Z. \& Cui, S. (2010). E-learning adoption intention and its key influence factors based on innovation adoption theory. Mathematical and Computer Modelling, Vol. 51, Issue 11-12, 1428-1432. https://doi.org/10.1016/j.mcm.2009.11.013

[8] King, E. \& Boyatt, R. (2015). Exploring factors that influence adoption of e-learning within higher education. BJET - British Journal of Educational Technololy, Vol. 46, Issue 6, 1272 1280.

[9] Kung, S. (2002). Factors that Affect Students'Decision to Take Distance Learning Courses: A Survey Study of Technical College Students in Taiwan. Educational Media International, Vol. 39, No 3/4, 299-305. https://doi.org/10.1080/09523980210166044

[10] Lai, C., Wang, Q. \& Lei J. (2012). What factors predict undergraduate students' use of technology for learning? A case from Hong Kong. Computers \& Education, Vol. 59, Issue 2, 569-579. https://doi.org/10.1016/j.compedu.2012.03.006

[11] Cheung, R. \& Vogel, D. (2013). Predicting user acceptance of collaborative technologies: An extension of the technology acceptance model for e-learning. Computer \& Education, Vol. 63, 160-175. https://doi.org/10.1016/j.compedu.2012.12.003

[12] Davis, F. (1989). Perceived usefulness, perceived ease of use, and user acceptance of information technology. MIS Quarterly, Vol. 13, No 3, 319-340. https://doi.org/10.2307/249008

[13] Venkatesh, V., Morris, M., Gordon, D. \&. Davis (2003). User acceptance of informattion technology: toward a unified view. MIS Quarterly Vol. 27, No 3, 425-478. $\underline{\text { https://doi.org/10.2307/30036540 }}$

[14] Jan, A. \& Contreras, V. (2011). Technology acceptance model for the use of information technology in universities. Computers in Human Behavior, Vol. 27, Issue 2, 845-851. https://doi.org/10.1016/j.chb.2010.11.009

[15] Liaw, S.-S. \& Huang, M.-M. (2011). A study of investigation learners attitudes toward elearning. IPCIT, Vol. 12. IACSIT Press, Singapore, 28-32.

[16] Abdullah, F. \& Ward, R. (2016). Developing a General Extended Technology Acceptance Model for E-Learning (GETAMEL) by analysing commonly used external factors. Computers in Human Behavior, Vol. 56, 238-256. https://doi.org/10.1016/j.chb.2015.11.036 
[17] Ibrahim, R., Leng, N., Yusoff, R., Samy, G., Masrom, S. \& Rizman, Z. (2017). E-Learning Acceptance Based on Technology Acceptance Model. Journal of Fundamental and Applied Science. 2017, Vol. 9 (4S), 871-889. https://doi.org/10.4314/jfas.v9i4S.50

[18] Sánchez, R. A., Hueros, A. D. \& Ordaz, M. G. (2013). E-learning and the University of Huelva: a study of WebCT and the technological acceptance model. Campus-Wide Information Systems, Vol. 30, Issue 2, 135-160. https://doi.org/10.1108/10650741311306318

[19] Park, S. Y. (2009). An Analysis of the Technology Acceptance Model in Understanding University Students' Behavioral Intention to Use e-Learning, Journal of Educational Technology \& Society, Vol. 12, No. 3, 150-162.

[20] Liu, I., Chen, M., Sun, Y., Wiblie, D. \& Kuo, C.H. (2010). Extending the TAM model to explore the factors that affect intention to use an online learning comunnity. Computers \& Education, Vol. 54, 600-610. https://doi.org/10.1016/j.compedu.2009.09.009

[21] Park, M. G., Nam M.H. \& Cha, S.-B. (2012). University students' behavioral intention to use mobile learning: Evaluating the technology acceptance model. British Journal of Educational Technology, Vol. 43, Issue 4, 592-605. https://doi.org/10.1111/j.1467$\underline{8535.2011 .01229 . X}$

[22] Y.-H. Lee, Y.-H., Hsiao, C. \& Purnomo, S. H. (2014). An empirical examination of individual and system characteristics on enhancing e-learning acceptance. Australasian Journal of Educational Technology, Vol. 30, No 5, 562-579. https://doi.org/10.14742/ajet.381

[23] Cakir, R. \& Solak, E. (2014). Exploring the Factors Influencing e-learning of Turkish EFL. TOJET: The Turkish Online Journal of Educational Technology, Vol. 13, Issue 3, 79-87.

[24] Marangunic, N. \& Granic, A. (2015). Technology acceptance model: a literature review from 1986 to 2013. Universal Access in the Information Society Heidelberg, Vol. 14, Issue 1, 81-95. https://doi.org/10.1007/s10209-014-0348-1

[25] Shroff, R. H., Deneen, C. C. \& Ng, E. M. W. (2011). Analysis of the technology acceptance model in examining students' behavioural intention to use an e-portfolio system. Australasian Journal of Educational Technology, Vol. 27, No 4, 600-618. https://doi.org/10.14742/ ajet. 940

[26] Lee, M.-C. (2010). Explaining and predicting users' continuance intention toward e-learning: An extension of the expectation-confirmation model. Computers \& Education, Vol. 54, 506-516. https://doi.org/10.1016/j.compedu.2009.09.002

[27] Martinho, D. (2014). O Ensino Online nas Instituições de Ensino Superior Privado. As perspetivas: docente e discente e as implicações na tomada de decisão institucional. Universidade de Lisboa: Tese de Doutoramento.

[28] Pestana, M. H. \& Gageiro, J. N. (2014). Análise de dados para Ciencias Sociais. Lisboa: Edições Sílabo.

[29] Hair, J., Black, W., Babin, B. \& Anderson, R. (2014). Multivariate Data Analysis. PrenticeHall.

[30] Tavakol, M. \& Dennick, R. (2011). Making sense of Cronbach's Alpha. International Journal of Medical Education. Vol. 2, 53-55. https://doi.org/10.5116/ijme.4dfb.8dfd

[31] Marôco, J. (2014). Análise de Equações Estruturais, Lisboa: ReportNumber.

[32] Fathema, N., Shannon, D. \& Ross, M. (2015). Expanding The Technology Acceptance Model (TAM) to Examine Faculty Use of Learning Management Systems (LMSs) in Higher Education Institutions. MERLOT Journal of Online Learning and Teaching Vol. 11, No 2, 210-232.

[33] Maroco, J. (2014). Análise Estatística com SPSS. Lisboa: Sílabo. 


\section{$7 \quad$ Authors}

Domingos Martinho is a teacher of computer science and Director of the Higher Institute of Management and Administration of Santarém. He has a master in computer science and $\mathrm{PhD}$ in education with specializing in e-learning from Lisbon University.

Eulália Santos is a teacher of applied math of the Higher Institute of Management and Administration of Santarém. She has a master and PhD in mathematics from Aveiro University.

$\mathbf{M}^{\mathbf{a}}$ Isabel Miguel has a teacher of language and communication of Higher Institute of Management and Administration of Santarém. She has a degree in Modern Languages and Literatures from Lisbon University and is currently developing her $\mathrm{PhD}$ thesis in business management.

Dina Cordeiro has a teacher of ITC of Higher Institute of Management and Administration of Santarém. She has a degree in applied math from Beira Interior University (Covilhã, PT) and is currently developing her master thesis in education.

Article submitted 21 May 2018. Final acceptance 08 June 2018. Final version published as submitted by the authors. 